\title{
Mitigation of Voltage Dip and Voltage Flickering by Multilevel D-STATCOM
}

\author{
M. S. Ballal, H. M. Suryawanshi, and T. Venkateswara Reddy \\ Visvesvaraya National Institute of Technology, Nagpur, India \\ Correspondence should be addressed to H. M. Suryawanshi, hms_1963@rediffmail.com
}

Received 3 May 2012; Accepted 19 July 2012

Academic Editor: Neville Watson

Copyright () 2012 M. S. Ballal et al. This is an open access article distributed under the Creative Commons Attribution License, which permits unrestricted use, distribution, and reproduction in any medium, provided the original work is properly cited.

The basic power quality problems in the distribution network are voltage sag (dip), voltage flickering, and the service interruptions. STATCOM is a Flexible AC Transmission Systems (FACTS) technology device which can independently control the flow of reactive power. This paper presents the simulation and analysis of a STATCOM for voltage dip and voltage flickering mitigation. Simulations are carried out in MATLAB/Simulink to validate the performance of the STATCOM. A comparison between the sixpulse inverter and the five-level diode-clamped inverter is carried out for the performance of 66/11 KV distribution system.

\section{Introduction}

STATCOM has got a much more widely application due to the advent of the concepts of the smart grid and the microgrid and the rapid development of new energy and the distributed generation. The Distributed Static Compensator (D-STATCOM) becomes the tendency of the reactive power compensation and the power quality control in distributing networks at the present time. It is of great significance to enhance the power quality and keep the relay protection devices working normally as it can make a comprehensive compensation to voltage fluctuation, voltage flicker, and three-phase unbalance. The output harmonic in DSTATCOM comes to our attention, as it is a member of the power electronic devices. The relationship between power quality and distribution system has been a subject of interest for several years.

The application of a high-voltage multilevel inverter in a $13.8 \mathrm{kV}$ distribution system Static Synchronous (SSC) is examined in [1]. The capability of the multi-level inverter to limit device voltage stress makes it suitable for highvoltage power conversion. A capacitor voltage balancing controller maintains operation of the multi-level inverter SSC under conditions of phase voltage imbalance shown in EMTP simulations. The concept of power quality describes the quality of the supplier voltage in relation to the transient breaks, falling voltage, harmonics, and voltage flicker. Utility distribution networks, sensitive industrial loads, and critical commercial operations suffer from various types of power quality problems like voltage sag, voltage flickering, service interruptions, and harmonics. The various characteristics of voltage sags experienced by customers within industrial distribution systems are described in [2]. The influence of the induction motor load on the characterization of voltage sags is discussed. It came to know that during a fault, an induction motor operates as a generator for a short period of time and causes an increase in sag magnitude. A microcomputer-based voltage flicker teaching facility consists of a single- and threephase voltage flicker generator, measurement devices, and a lamp test system is described in [3]. Information obtained by the facility includes understanding the causes and the influences of voltage flicker, voltage flicker measurement, and the realistic illuminating flicker phenomena.

Topologies like diode-clamped inverter (neutral-point clamped), capacitor clamped (flying capacitor), and cascaded multicell with separate dc sources are presented in [4]. The relevant control and modulation methods are discussed with multilevel sinusoidal pulse width modulation, multilevel selective harmonic elimination, and space-vector modulation. However, only the fundamental principle of different multilevel inverters has been introduced systematically. A voltage dip is a short-time (10 ms to 1 minute) event 
during which a reduction in r.m.s voltage magnitude occurs. It is often set only by two parameters, depth/magnitude, and duration. The voltage dip magnitude is ranged from $10 \%$ to $90 \%$ of nominal voltage (which corresponds to $90 \%$ to $10 \%$ remaining voltage) and with a duration from half a cycle to $1 \mathrm{~min}$. In a three-phase system a voltage dip is by nature a three-phase phenomenon, which affects both the line-toground and line-to-line voltages. A voltage dip is caused by a fault in the utility system, a fault within the customer's facility or a large increase of the load current, like starting a motor or transformer energizing. The high current results in a voltage drop over the network impedance.

A STATCOM configuration is described in [5] that combines the advantages of the diode clamped, d.c. voltage reinjection VSC, and soft switching concepts. This scheme uses asymmetrical switches instead of diodes in a common clamping switching circuit for the three phases of the converter bridges. The theoretical analysis, backed by EMTDC simulation, is carried out. A method of modelling and control strategies for fast load voltage regulation using STATCOMs is described in [6]. Another power quality problem is voltage flicker, a phenomenon of annoying light intensity fluctuation, caused by large rapid industrial load changes. Erratic variations in reactive power demands lead to fluctuating voltage drops across the impedance of a distribution system which results in voltage flicker. Voltage flicker occurs when large industrial loads, such as electric arc furnaces, rolling mills, large mine hoists, resistance welders, and pumps operating in a weak power distribution system. The modelling strategy, similar to that used for field-oriented control of ac machines, defines the bus voltage magnitude and reactive current input from the STATCOM on an instantaneous basis. The particular coordinate transform used also facilitates extraction of liberalized system dynamics with the help of circuit simulators having analogue behavioural modelling capabilities. In order to accurately determine the frequency response of a multilevel converter, it is necessary to consider the dc voltage polluted with ac ripple, for the duration of conduction periods. Analytical formulae for a single cell and for a generic cascade multilevel converter where the number of cells is a parameter are presented in [7]. The testing is performed in digital simulation in PSCAD. An analytical framework for minimizing losses and harmonics is presented for the cascaded-type-based multilevel static synchronous compensator (STATCOM) with square-wave control being discussed in [8]. The focus lays on low losses, low-voltage total harmonic distortion (THD), and low dc voltage ripple. Digital simulations are used in PSCAD.

Variation on the typical MPC control scheme for a H-Stat Com which provides excellent current tracking performance while simultaneously trading off the voltage balancing characteristics with the switching losses is presented in [9]. The scheme consists of a dead-beat current controller that has been integrated with heuristic models of the voltage balancing and switching loss characteristics. System configuration and a control method for a multivoltage cascade converter in order to reduce power loss and volume of a $6.6-\mathrm{kV}$ transformer less D-STATCOM are proposed in [10]. Downscaled STATCOM model verification tests are executed restricted to rates at $220 \mathrm{~V}$ and $10 \mathrm{kVA}$. Some of the drawbacks of voltage flicker were explained in the literature [4-8] and the IEEE Standard 519-1992, which is referred widely, defines maximum permissible voltage flicker levels with respect to frequency as shown in Figure 1.

In this paper, two D-STATCOM controllers based on six-pulse inverter and five-level diode-clamped inverter are proposed. Both strategies are simulated using MATLAB/ Simulink models. Simulation results confirming the effectiveness of the control schemes to impose a linear STATCOM dynamics are presented.

\section{Dynamic Model of D-STATCOM}

D-STATCOM is one of the most recent FACTS devices for power transmission shunt compensation. It is shuntconnected device which was developed as a static VAR compensator where a Voltage Source Converter (VSC) is used instead of controllable reactors. The STATCOM can be seen as a current source since it is connected in shunt with the distribution system and the load. By controlling the magnitude and the phase angle of the output voltage of the VSC, both active and reactive power can be exchanged between the distribution system and the STATCOM. Being a shunt-connected device, the STATCOM mainly injects reactive power to the system [3]. Radial system with STACOM is shown in Figure 2. $R_{d}$ is included to represent small losses in the switching devices of VSC. The space vector diagram for voltages and currents is shown in Figure 3, where $\alpha \beta$ axes represent stationary reference frame and $d q$ axes represent synchronous rotating reference frame. The equivalent circuit of the tie transformer between bus voltage $V_{t}$ and $V_{i}$ is represented by $R$ and $L$. The circuit equation in respect of stationary reference frame can be written as below:

$$
L \frac{d i}{d t}+R i=V_{t}-V_{i}
$$

The stationary reference frame in terms of synchronously rotating reference frame is illustrated by the following equation:

$$
V_{t} e^{-j \lambda}=v_{t d}+j v_{t q}
$$

This can be elaborated with angle $\delta$ in respect of Figure 3 and thus it is written as

$$
V_{i} e^{-j \lambda}=v_{i d}+j v_{i q}=V_{i} e^{-j \delta}=v_{i} \cos \delta-j v_{i} \sin \delta .
$$

Corresponding current equation is given as

$$
i e^{-j \lambda}=i_{d}+j i_{q} .
$$

The relationship between current and voltage equation is shown by the following equation:

$$
L e^{-j \lambda} \frac{d i}{d t}+R e^{-j \lambda} i=V_{t} e^{-j \lambda}-V_{i} e^{-j \lambda} .
$$




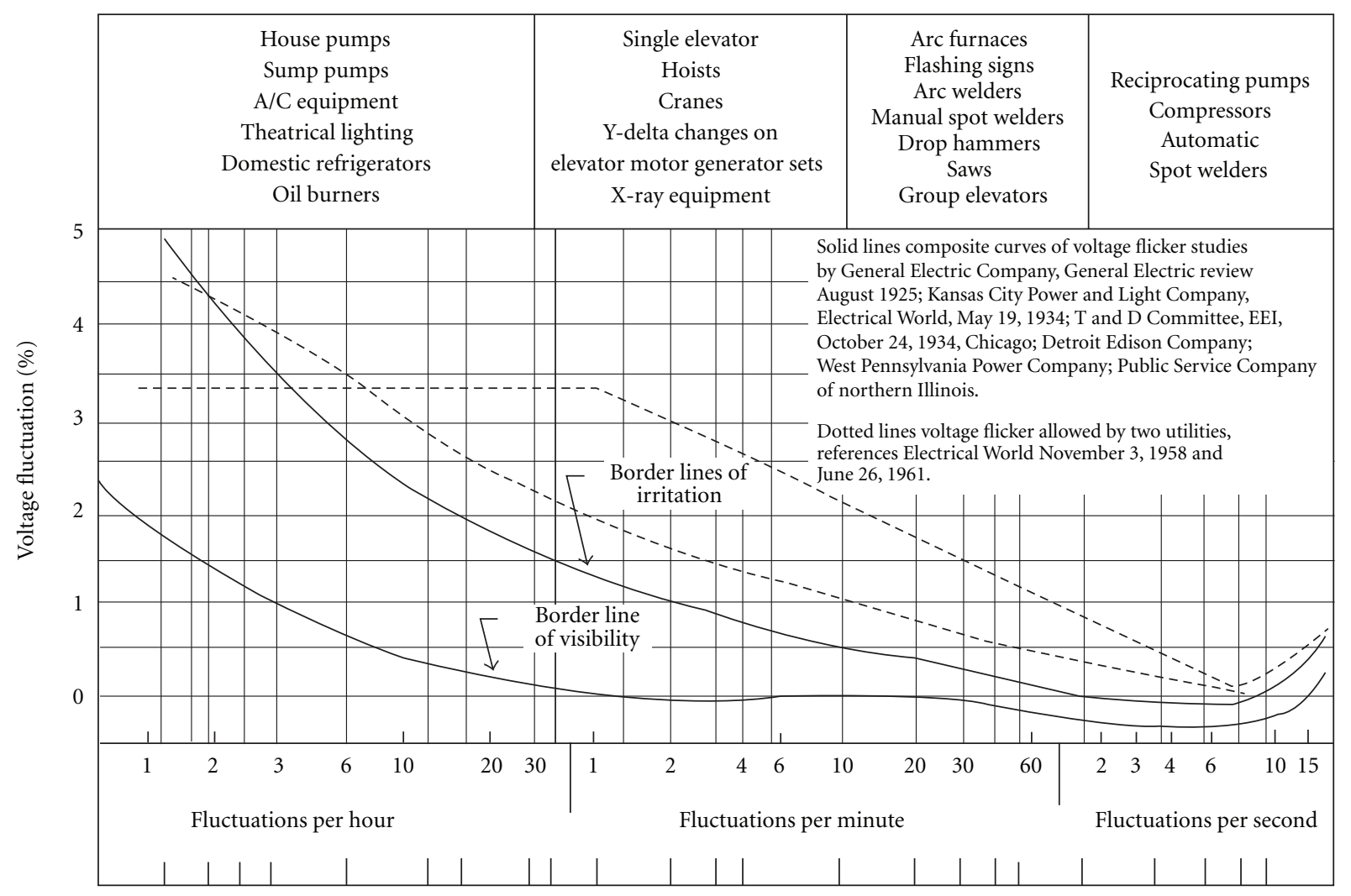

Figure 1: Flickering curve.

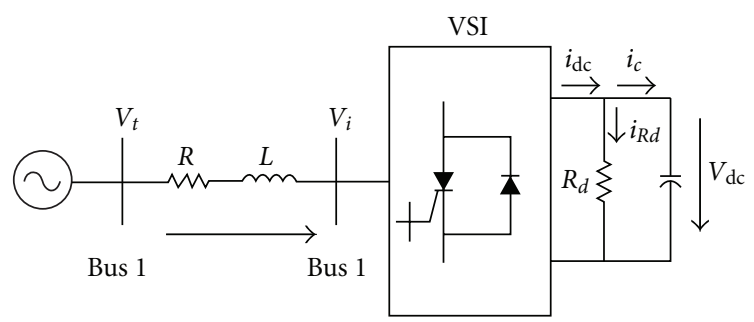

FIGURE 2: D-STATCOM configuration on the radial system.

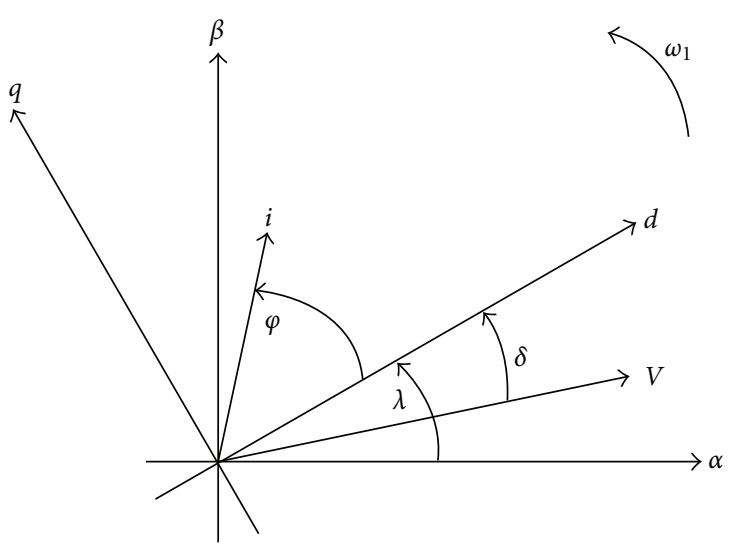

FIGURE 3: State vector diagram.
Substituting (2), (3), and (4) into (1) and rearranging, voltage equations for real part in $d$-axis and for imaginary part in $q$-axis are

$$
\begin{aligned}
& L \frac{d i_{d}}{d t}+R i_{d}=u_{t d}-m V_{\mathrm{dc}} \cos \delta+L \omega_{1} i_{q}, \\
& L \frac{d i_{q}}{d t}+R i_{q}=u_{t q}-m V_{\mathrm{dc}} \sin \delta-L \omega_{1} i_{d},
\end{aligned}
$$

where $\omega_{1}$ is system frequency. The magnitude of phase voltage at bus $2\left(V_{i}\right)$ is directly proportional to the DC voltage across the capacitor $V_{\mathrm{dc}}$ and therefore can be expressed as

$$
V_{i}=m V_{\mathrm{dc}}
$$

The value of $m$ is proportional depending on the type of VSC. If the dc current $\left(i_{\mathrm{dc}}\right)$ is defined as the sum of capacitor current $\left(i_{c}\right)$ and resistor current $\left(i_{R d}\right)$, the power flows into VSC and is described as

$$
p=V_{\mathrm{dc}} i_{\mathrm{dc}}=\frac{3}{2}\left(v_{d} i_{d}+v_{q} i_{q}\right) .
$$

From (3), (7), and (8), the dc current is given as

$$
i_{\mathrm{dc}}=\frac{3}{2} m\left(i_{d} \cos \delta-i_{q} \sin \delta\right)=C \frac{d V_{\mathrm{dc}}}{d t}+\frac{V_{\mathrm{dc}}}{R_{d}} .
$$


Equations (6) and (9) form a state equation for STATCOM:

$$
\begin{aligned}
\frac{d}{d t}\left[\begin{array}{c}
i_{d} \\
i_{q} \\
V_{\mathrm{dc}}
\end{array}\right] & {\left[\begin{array}{ccc}
-\frac{1}{T_{1}} & \omega_{1} & -\frac{m}{L} \cos \delta \\
-\omega_{1} & -\frac{1}{T_{1}} & \frac{m}{L} \sin \delta \\
\frac{3}{2} \frac{m}{c} \cos \delta & -\frac{3}{2} \frac{m}{c} \sin \delta & -\frac{1}{T_{1}}
\end{array}\right]\left[\begin{array}{c}
i_{d} \\
i_{q} \\
V_{\mathrm{dc}}
\end{array}\right] } \\
+ & {\left[\begin{array}{cc}
\frac{1}{L} & 0 \\
0 & \frac{1}{L} \\
0 & 0
\end{array}\right] \quad\left[\begin{array}{c}
v_{t d} \\
v_{t q}
\end{array}\right] }
\end{aligned}
$$

where $T_{1}=L / R, T_{2}=R_{d} C$.

Linearization of (10) around the operating firing angle, $\delta_{0}$, gives a set of linear equations as shown in:

$$
\begin{aligned}
& \frac{d}{d t}\left[\begin{array}{c}
i_{d} \\
i_{q} \\
V_{\mathrm{dc}}
\end{array}\right] \\
& =\left[\begin{array}{ccc}
-\frac{1}{T_{1}} & \omega_{1} & -\frac{m}{L} \cos \delta_{0} \\
-\omega_{1} & -\frac{1}{T_{1}} & \frac{m}{L} \sin \delta_{0} \\
\frac{3}{2} \frac{m}{c} \cos \delta_{0} & -\frac{3}{2} \frac{m}{c} \sin \delta_{0} & -\frac{1}{T_{1}}
\end{array}\right] \\
& \times\left[\begin{array}{c}
i_{d} \\
i_{q} \\
V_{\mathrm{dc}}
\end{array}\right] \\
& +\left[\begin{array}{ccc}
\frac{1}{L} & 0 & \frac{m}{L} V_{\mathrm{dc} 0} \sin \delta_{0} \\
0 & \frac{1}{L} & \frac{m}{L} V_{\mathrm{dc} 0} \cos \delta_{0} \\
0 & 0 & -\frac{3}{2} \frac{m}{c}\left(i_{d 0} \sin \delta_{0}+i_{q 0} \cos \delta_{0}\right)
\end{array}\right] \\
& \times\left[\begin{array}{c}
v_{t d} \\
v_{t d} \\
\delta
\end{array}\right] .
\end{aligned}
$$

The characteristic equation of the system described by (11) is

$$
\begin{aligned}
S^{3} & +\left\{\frac{2}{T_{1}}+\frac{1}{T_{2}}\right\} S^{2}+\left\{\frac{2}{T_{1} T_{2}}+\frac{1}{T_{1}^{2}}+K+\omega_{1}^{2}\right\} S \\
& +\left\{\frac{1}{T_{1}^{2} T_{2}}+\frac{K}{T_{1}}+\frac{\omega_{1}^{2}}{T_{2}}\right\}=0,
\end{aligned}
$$

where $K=(3 / 2)\left(m^{2} / L C\right)$.

The characteristic equation is not a function of firing angle. Hence, firing angle does not affect the position of characteristic roots on the complex plane.

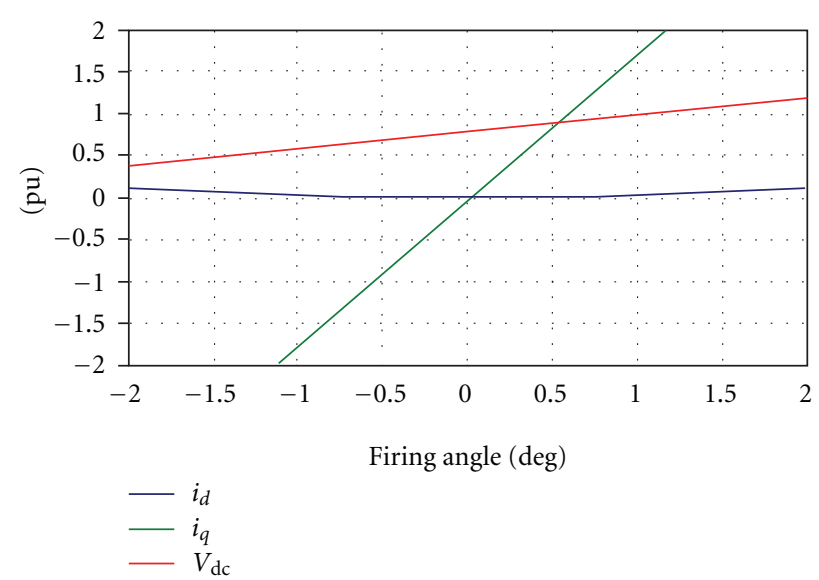

Figure 4: Steady-state response.

2.1. Stability Test of STATCOM Model. The stability of STATCOM can be tested with Routh-Hurwitz criterion. By assigning $p, q$, and $r$ to represent the coefficients of $s^{2}, s^{1}$, and $s^{0}$, respectively, (12) becomes $s^{3}+p s^{2}+q s+r=0$ and the Routh's Array equation can be written as

$$
\begin{array}{lcc}
s^{3} & 1 & q \\
s^{2} & p & r \\
s^{1} & q-\frac{r}{p} & \\
s^{0} & \multicolumn{2}{c}{r}
\end{array}
$$

Substitute $p, q$, and $r$ to determine the element in the $s^{1}$ row:

$$
q-\frac{r}{p}=\frac{4}{T_{1}}+\frac{2}{T_{2}}+\frac{2 T_{2}}{T_{1}^{2}}+K T_{2}+K T_{1}+2 \omega_{1}^{2} T_{2} \geq 0 .
$$

Examination of all elements in the first column of Routh's array reveals that all elements are positive, and the STAT$\mathrm{COM}$ is a stable system. Therefore, the values of resistors, inductors, and capacitors in the STATCOM equivalent circuit have no effect on stability.

2.2. Steady-State Analysis. Equation for the steady state operation of STATCOM can be obtained from the dynamic model by setting all derivative terms to zero. After transformation into $d-q$ reference frame, voltages and current become DC quantities, that is, $V_{t d}=V_{t}, v_{t q}=0, i_{d}=I_{d}, i_{q}=I_{q}$. Rearranging and assigning $X$ for $\omega_{1} L$, steady state equation becomes

$$
\left[\begin{array}{ccc}
-R & X & -m \cos \delta \\
-X & -R & m \sin \delta \\
3 m \cos \delta & -3 m \sin \delta & -\frac{2}{R_{d}}
\end{array}\right]\left[\begin{array}{c}
I_{d} \\
I_{q} \\
V_{\mathrm{dc}}
\end{array}\right]=-\left[\begin{array}{c}
V_{t} \\
0 \\
0
\end{array}\right]
$$




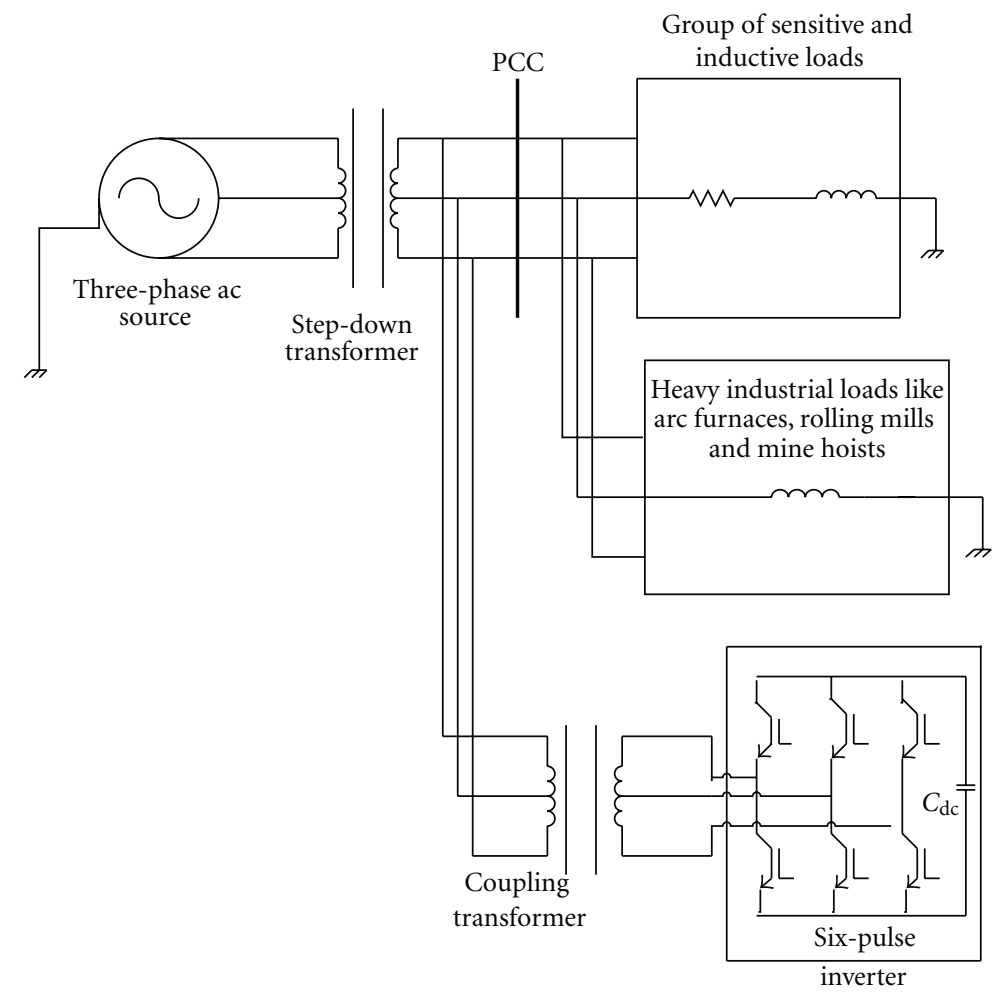

(a)

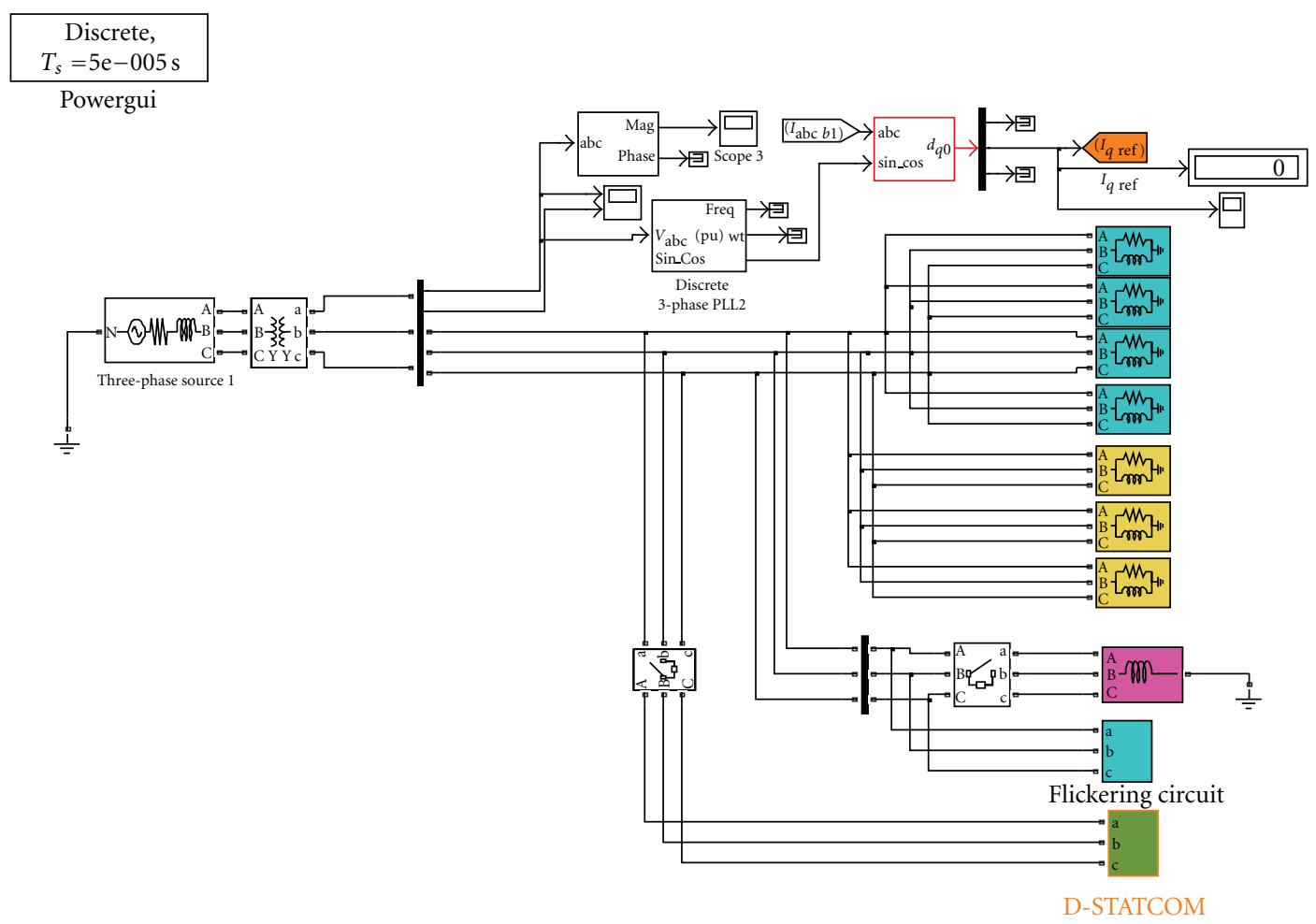

(b)

FIgURE 5: (a) Circuit implementation of the D-STATCOM with the six-pulse inverter. (b) MATLAB Simulation model for D-STATCOM with 6-pulse converter for mitigation of voltage dip and voltage flickering. 


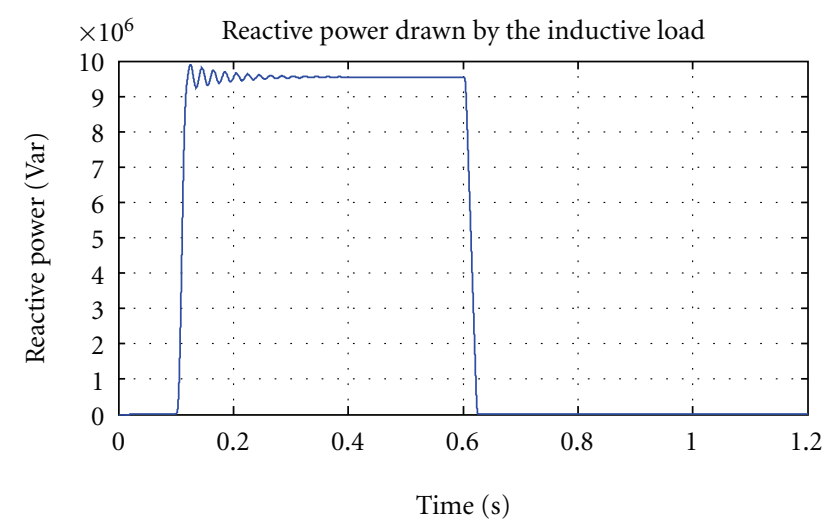

FIGURE 6: Reactive power drawn at the time of applying the inductive load.

Solving for $I_{d}, I_{q}$, and $V_{\mathrm{dc}}$, the solutions are

$$
\begin{aligned}
I_{d} & =\frac{R+(3 / 2) m^{2} R_{d} \sin ^{2} \delta}{R^{2}+x^{2}+(3 / 2) m^{2} * R * R_{d}} V_{t}, \\
I_{q} & =\frac{-x+(3 / 2) m^{2} R_{d} \sin \delta \cos \delta}{R^{2}+x^{2}+(3 / 2) m^{2} * R * R_{d}} V_{t}, \\
V_{\mathrm{dc}} & =\frac{(3 / 2) m R_{d}(R \cos \delta+x \sin \delta)}{R^{2}+x^{2}+(3 / 2) m^{2} * R * R_{d}} V_{t} .
\end{aligned}
$$

The equations of direct current, quadrature current, and capacitor voltage do not contain capacitor. Hence, the size of dc capacitor does not affect STATCOM steady state performance. Especially, the quadrature current, which is reactive current $\left(i_{q}\right)$, does not depend on the size of dc capacitor. The steady state performances were calculated with the following parameters: $R=0.01 \mathrm{pu}, X=0.15 \mathrm{pu}, R_{d}=$ $128 \mathrm{pu}, C=0.013 \mathrm{pu}$, and $m=4 / \pi$. The plot of active current $i_{d}$, reactive current $I_{q}$, and capacitor voltage $V_{\mathrm{dc}}$ as a function of firing angle is shown in Figure 4.

At steady state, the reactive current $\left(i_{q}\right)$ is a linear function of firing angle within this operating range. With advanced firing angle ( $\delta$ is negative), the reactive current flows into the STATCOM and vice versa. The capacitor voltage $\left(V_{\mathrm{dc}}\right)$ increases linearly with firing angles (from advanced angles to delayed angles). The active current $\left(i_{d}\right)$ is small and varies very little with firing angle because it only furnishes the losses in the VSC.

\section{Simulation Studies}

Verification of the proposed control strategies was accomplished through simulation studies using a detailed model of a three-phase STATCOM implemented in MATLAB/Simulink. The test data taken for simulation is given in the Appendix. For easy comparison of the performance of a STATCOM under the proposed control schemes, results concerning the six-pulse inverter are presented first.

3.1. Simulation Results for STATCOM with Six-Pulse Inverter. In this case, the D-STATCOM is prepared with six-pulse

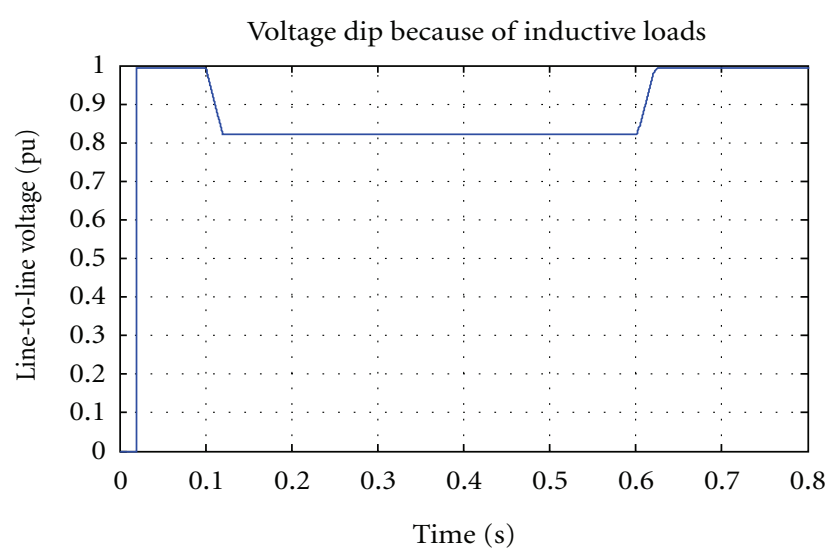

FIGURE 7: Voltage dip representation because of the sudden switching of inductive loads.

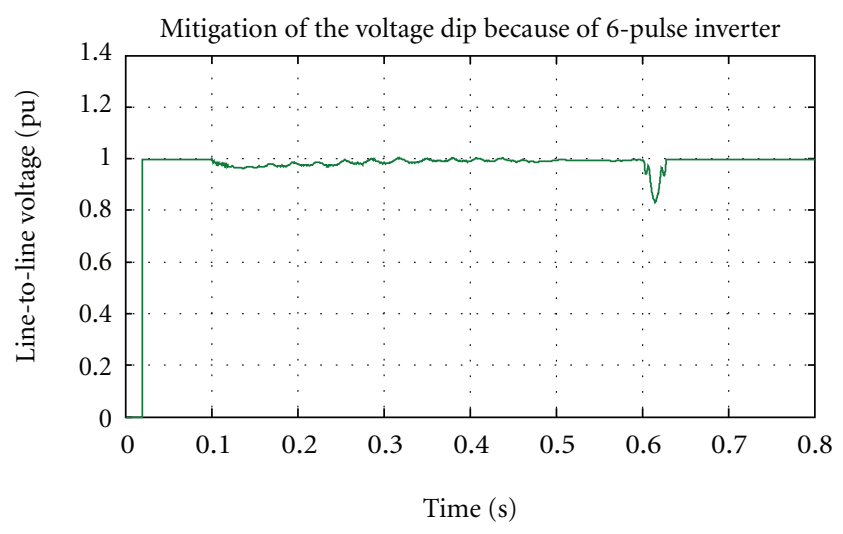

Figure 8: Voltage dip mitigation because of the application of sixpulse inverter.

inverter. The complete $66 / 11 \mathrm{KV}$ utility distribution system is shown in Figure 5(a). The circuit consists of a utility system and a step down transformer to step-down the voltage level to distribution side. In this system, all kinds of loads like industrial, commercial, domestic, and even sensitive loads can be connected to the point of common coupling (PCC). In this paper, heavy inductive load is connected to the system for the simulation purpose. The reactive current $\left(I_{q}\right)$ mentioned in (17) is injected at PCC for the mitigation of voltage dip and voltage flickering. The MATLAB Simulation model for D-STATCOM with 6-pulse converter for mitigation of voltage dip and voltage flickering is shown in Figure 5(b). The ratings of the system are specified in the above section. In order to analyze the system for the power quality problems, simulation was done as described in following cases.

Case 1 (voltage dip). Initially, the D-STATCOM is not connected to the system and the load of pure inductive of 10 MVAR is applied on the system in the time interval of $0.1 \mathrm{sec}$ to $0.6 \mathrm{sec}$ as shown in Figures 6 and 7. The voltage got dipped from 0.9955 p.u to 0.8205 p.u. Now, the DSTATCOM is connected in the circuit; the voltage profile at PCC is maintained at 0.9652 . Here, the excessive reactive 


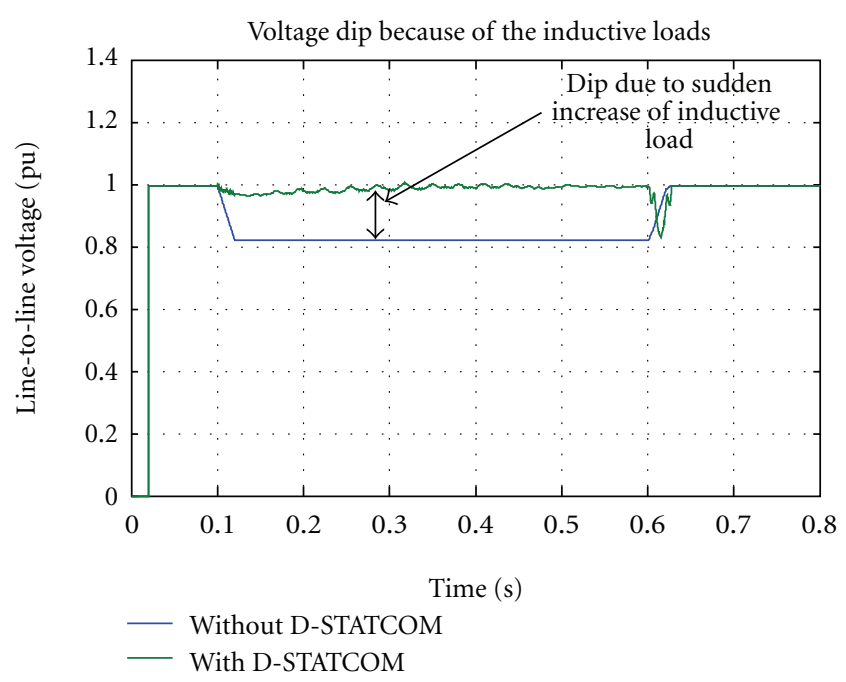

FIgure 9: Comparison of with and without D-STATCOM with sixpulse inverter.

power drawn by the load is supplied by the D-STATCOM than by the system. So at that instant STATCOM acts like capacitor. The response of control circuit with the six-pulse D-STATCOM is shown in Figures 8 and 9.

Case 2 (voltage flickering). The flickering circuit prepared with the help of R-L load which is periodically operated on the system causes the voltage flickering at the PCC (bus1) as shown in Figure 10. The magnitude of flickering level without the D-STATCOM in the circuit is $2.09 \%$ which is above the tolerable limits. After keeping the D-STATCOM in the circuit, the flickering level comes down to $0.68 \%$ which is below the threshold of objection shown in Figure 11. The 10 MVAR D-STATCOM contains a PWM IGBT inverter, $5800 \mu \mathrm{F} \mathrm{dc}$ capacitor, and a control system. The PWM generator with a $3 \mathrm{kHz}$ carrier frequency generates pulses for the IGBT inverter. The D-STATCOM is connected to the $11 \mathrm{kV}$ bus through an $11 / 2 \mathrm{kV}$ coupling transformer.

The instantaneous current of the D-STATCOM is obtained by $a b c_{-} t o_{-} d q 0$ transformation. The decoupled $d$-axis component $i_{d}$ and $q$-axis component $i_{q}$ are regulated by two separate PI regulators. The instantaneous $i_{q}$ reference is obtained from the measurement of reactive current produced by the inductive load. The $i_{d}$ current corresponds to the small active power absorbed by the D-STATCOM due to the losses in the transformer and in the inverter. This is referring to (15)-(17). The DC bus voltage is also regulated to compensate for the real power losses. In this direct current control strategy, the reference values $\left(i_{q \text { ref }}, i_{d \text { ref }}\right)$ and feedback values $\left(i_{q}, i_{d}\right)$ are the dc signals; therefore the instantaneous current tracing control with no steady-state error can be implemented using PI control. FFT transformation of sixpulse inverter is depicted in Figure 12.

3.2. Simulation Results for STATCOM with Five-Level Inverter. In this case, the D-STATCOM is prepared with five-level

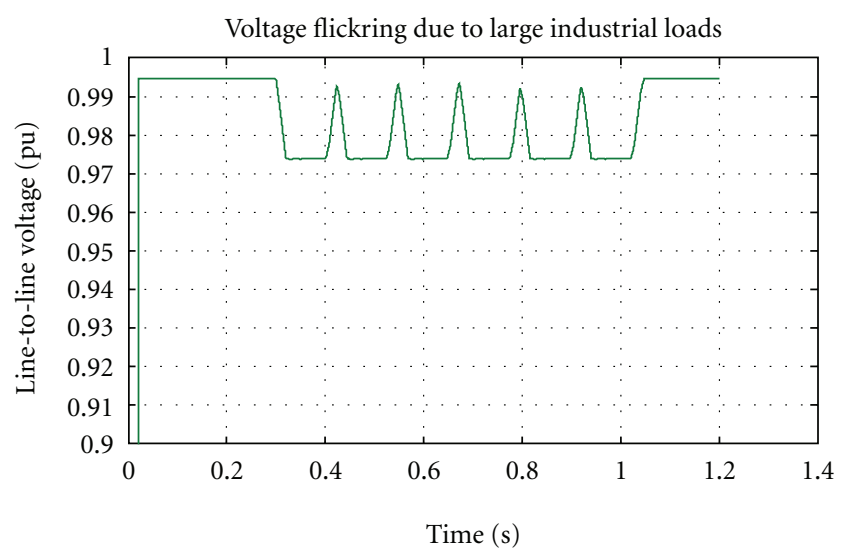

FIGURE 10: Voltage flickering because of the inductive loads likes electric arc furnaces and rolling mills.

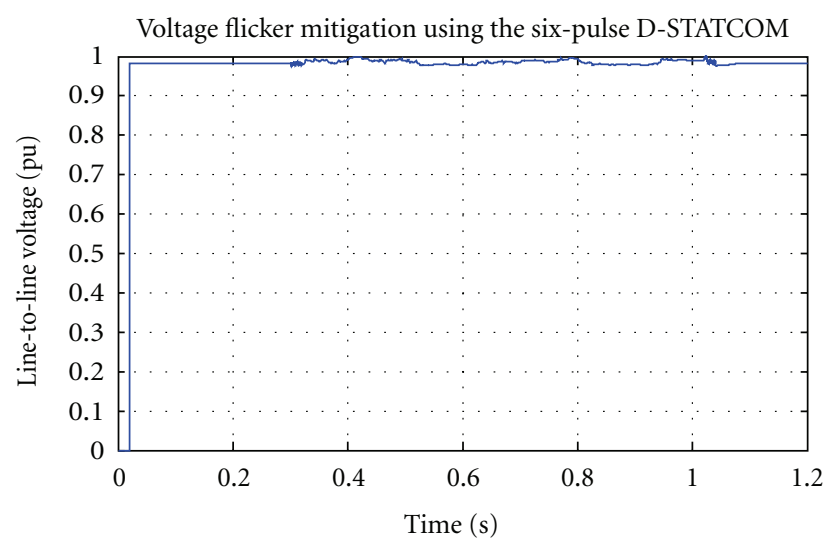

FIGURE 11: Voltage flicker mitigation by applying the D-STATCOM six-pulse inverter.
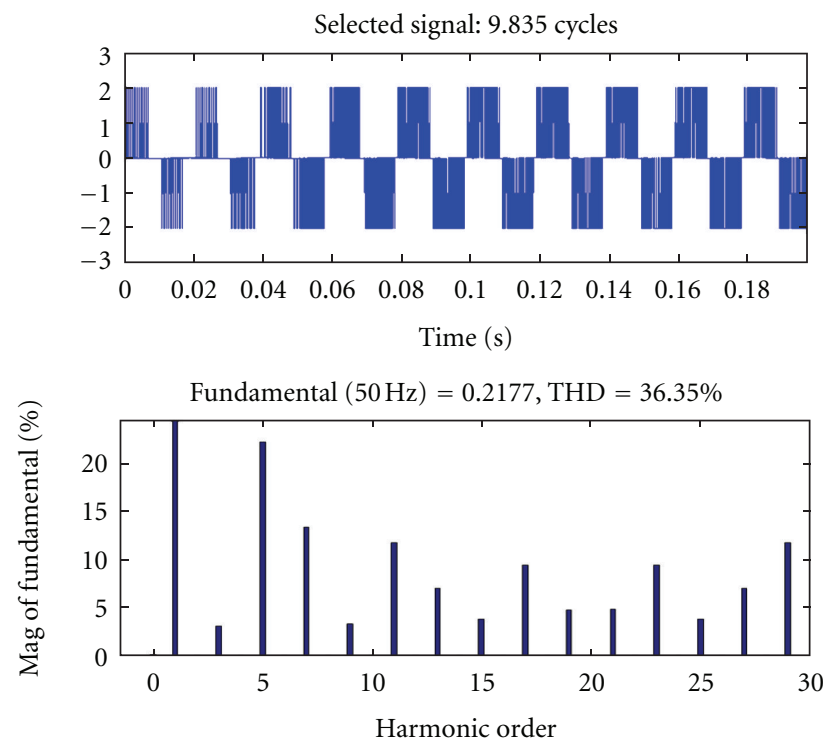

FIGURE 12: FFT transformation of six-pulse inverter. 
Group of sensitive and inductive loads

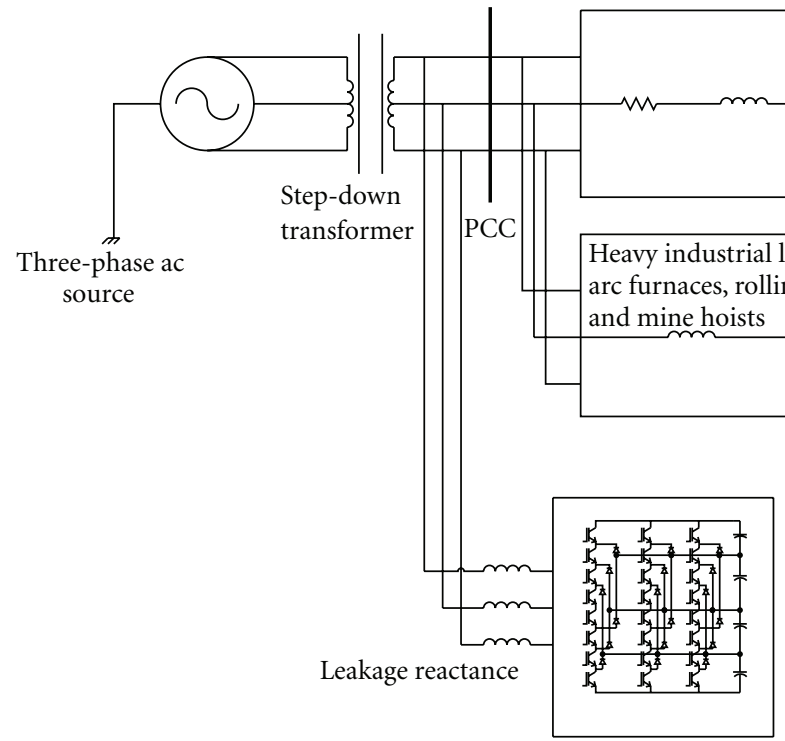

Five-level diode-clamped inverter

(a)

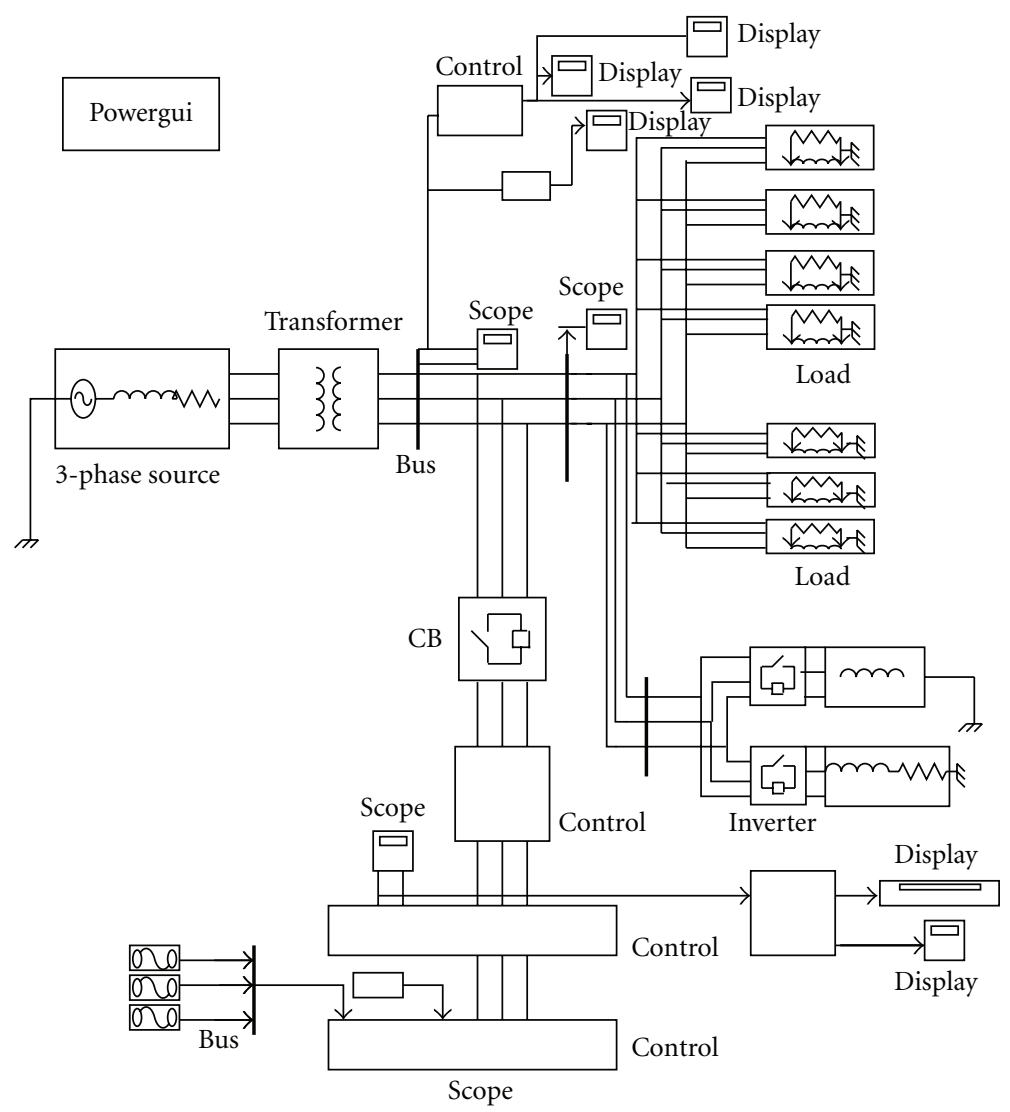

(b)

FIGURE 13: (a) Voltage dip because of the sudden application of the inductive loads. (b) MATLAB Simulation modal for D-STATCOM with five-level inverter for mitigation of voltage dip and voltage flickering. 


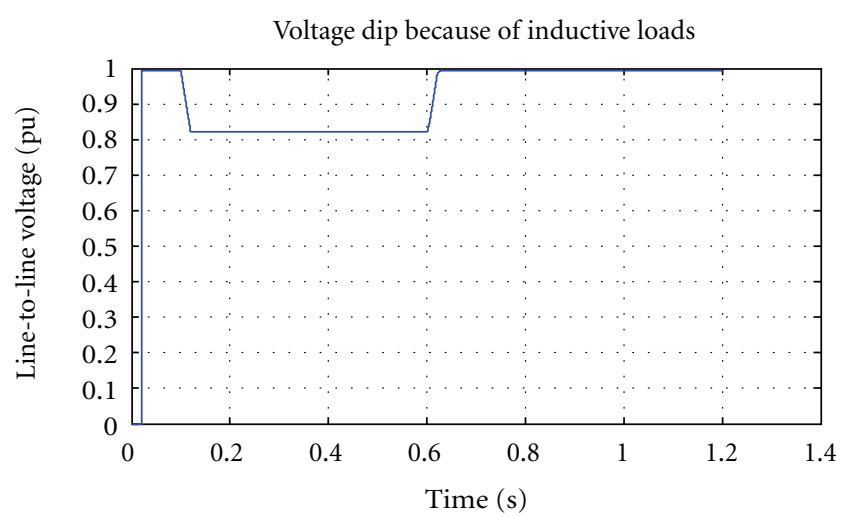

FIGURE 14: Voltage dip because of the sudden application of the inductive loads.

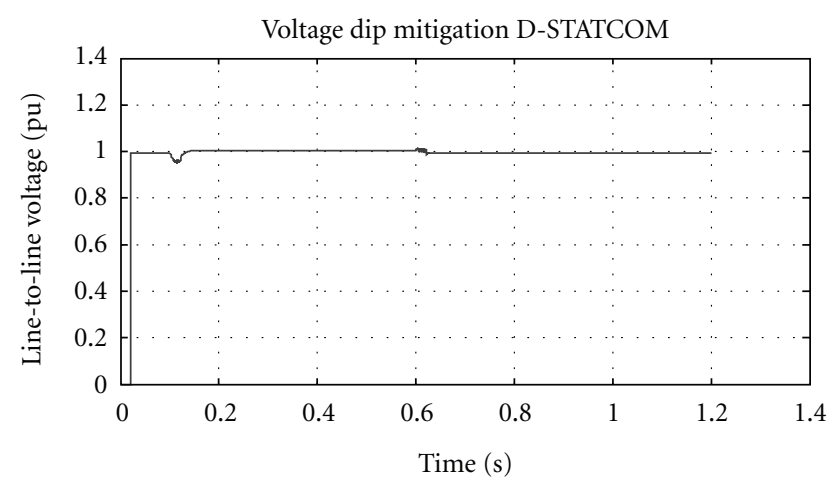

FIGURE 15: Voltage dip mitigation by D-STATCOM five-level diode clamped.

diode-clamped multilevel inverter. The complete 66/11 KV utility distribution system is shown in Figure 13(a). In this system, also all kind of loads like industrial, commercial, domestic, and even sensitive loads can be connected to the point of common coupling (PCC). Here again, heavy inductive load is connected to the system for the simulation purpose. The MATLAB Simulation modal for D-STATCOM with five-level inverter for mitigation of voltage dip and voltage flickering is shown in Figure 13(b). In order to analyze the system for the power quality problems, simulation was done as described in the previous section with similar cases.

Case 1 (voltage dip). Initially, the D-STATCOM is not connected to the system and the load of pure inductive of 10 MVAR is applied on the system in the time interval of $0.1 \mathrm{sec}$ to $0.6 \mathrm{sec}$ as shown in Figure 14. The voltage got dipped from 0.9955 p.u to 0.8205 p.u. Now, the D-STATCOM is connected in the circuit; the voltage profile at the point of common coupling (PCC) is maintained at same value of 0.9955 p.u. This is except some switching transients. Here, the excessive reactive power drawn by the load is supplied by the DSTATCOM than by the system. Therefore, at this instant STATCOM acts like capacitor.

Case 2 (voltage flickering). The flickering circuit is prepared with the help of R-L load which is periodically operated on

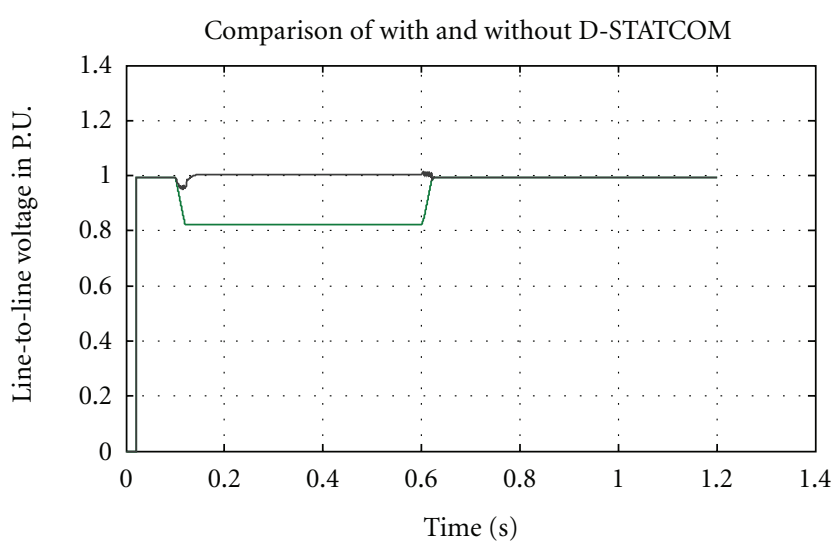

- Without D-STATCOM

FIGURE 16: Comparisons of voltage dip mitigation with and without D-STATCOM having five-level inverter.

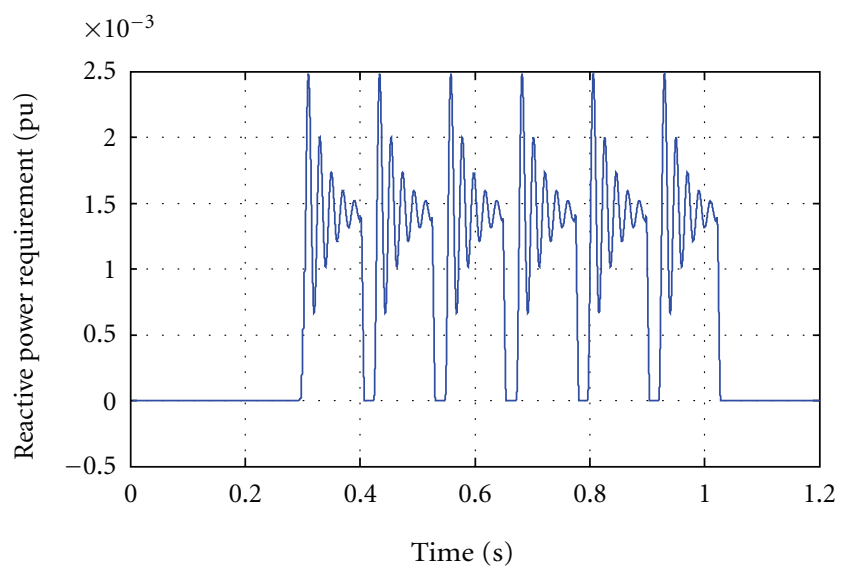

Figure 17: Reactive power drawn because of flickering loads.

the system cause the voltage flickering at the bus1 (PCC). The magnitude of flickering level without the D-STATCOM in the circuit is $2.09 \%$ which is above the tolerable limits. The voltages dip mitigation is shown in Figure 15 and the comparison is shown in Figure 16 for five-level inverter. The reactive power and voltage flickering are shown in Figures 17 and 18, respectively. After keeping the D-STATCOM in the circuit the flickering level comes down to $0.29 \%$ which is below the threshold of objection as shown in Figure 19 and the comparison is depicted in Figure 20. The output voltage and FFT of five-level diode-clamped multilevel inverter are shown in Figure 21. The complete STATCOM control system scheme is implemented and the performance is checked for both types of inverters. Output voltage is mitigated by both the STATCOM circuitries and its results are depicted in relevant figures. In these cases, the voltage flicker is also mitigated and improved voltage waveform is obtained. Furthermore, it is clearly observed from Table 1 that the mitigation of the power quality problems (voltage dip and the voltage flickering), done effectively with the five-level 
TABle 1: Performance comparison between the six-pulse and the five-level diode-clamped inverters.

\begin{tabular}{lcccc}
\hline Type of inverter & D-STATCOM status & T.H.D. of $V_{\mathrm{ab}}$ & Voltage flickering & Voltage dip \\
\hline Five-level diode-clamped inverter & Off & $12.16 \%$ & $2.09 \%$ & $0.29 \%$ \\
& On & & $2.09 \%$ & $0.00005 \%$ \\
Six-pulse inverter & Off & $36.35 \%$ & $0.68 \%$ & $17.50 \%$ \\
& On & & $3.043 \%$ \\
\hline
\end{tabular}

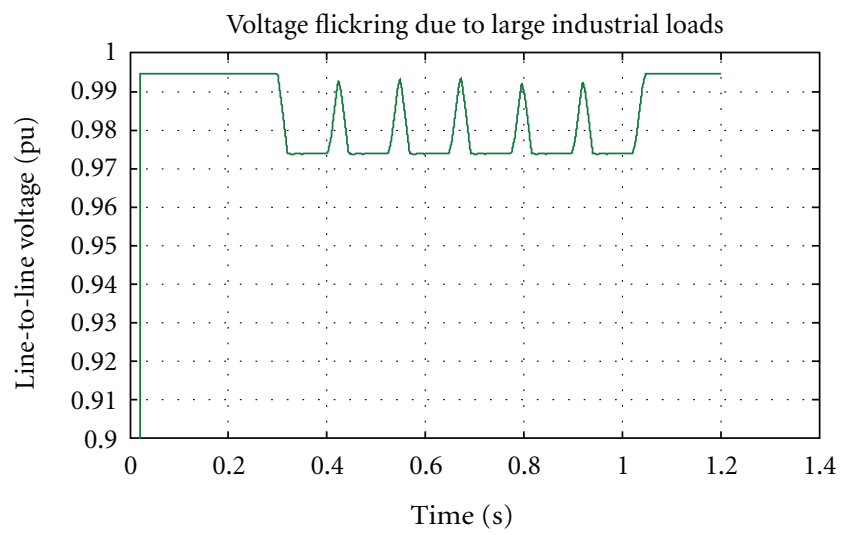

FIGURE 18: Voltage flickering.

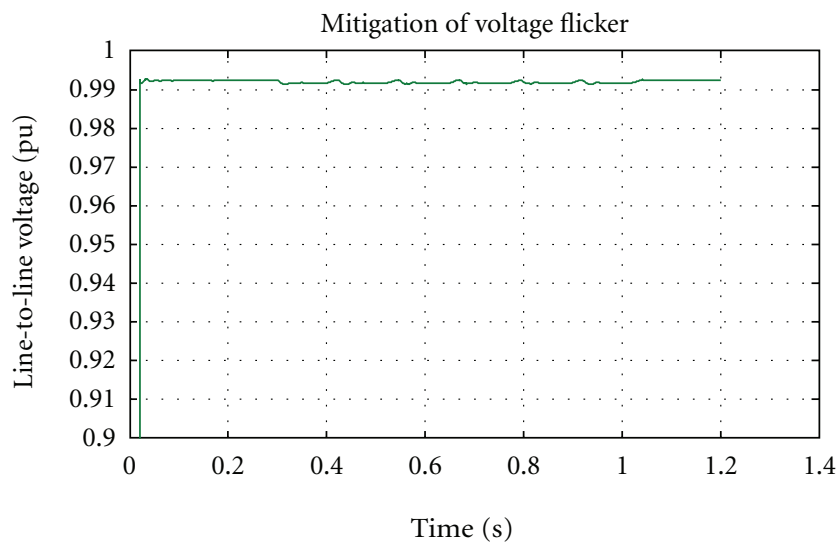

FIGURE 19: Voltage flicker mitigation because of five-level diodeclamped inverter D-STATCOM.

diode-clamped multilevel inverter D-STATCOM than with the six-pulse inverter D-STATCOM.

\section{Conclusion}

Voltage dip and voltage flickering are the two major power quality problems which are frequently seen in the distribution systems. These power quality problems in $66 / 11 \mathrm{KV}$ distribution system are investigated in this paper. The analysis and simulation of a D-STATCOM application for the mitigation of power quality problems are presented and discussed. Here, the D-STATCOM was prepared with the sixpulse inverter and the five-level diode-clamped multilevel

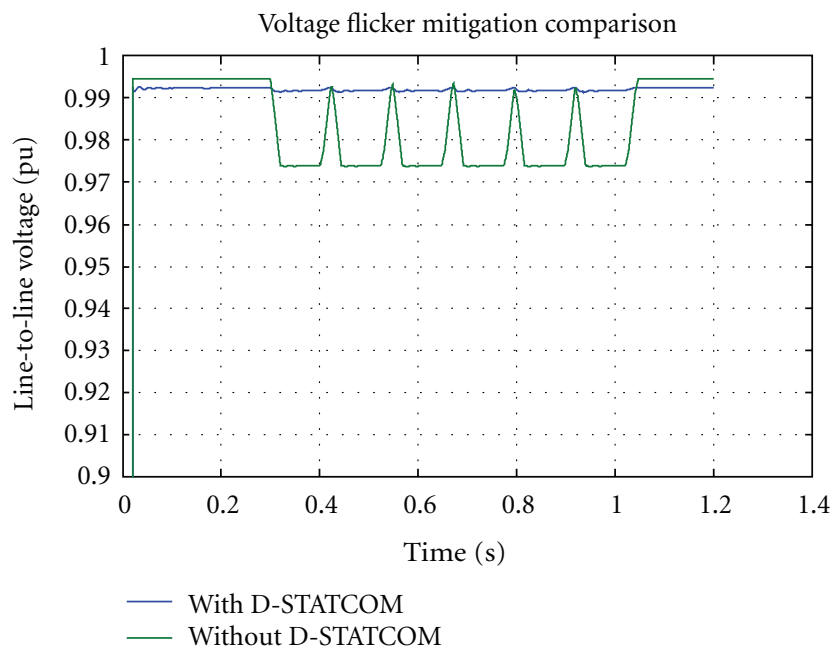

FIGURE 20: Comparison of voltage flicker mitigation with and without D-STATCOM.
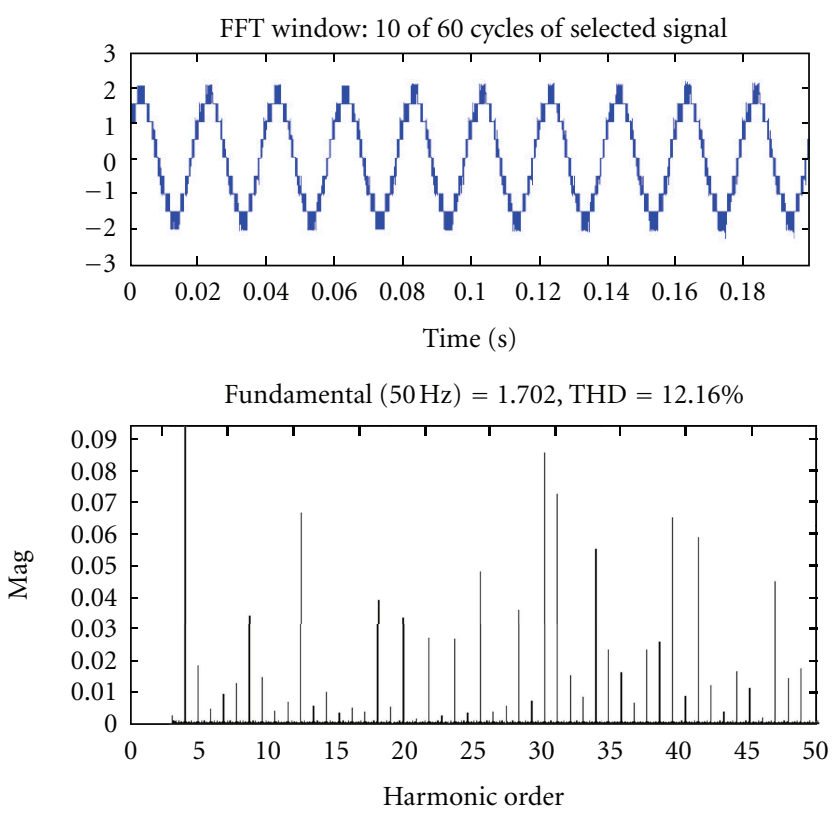

FIGURE 21: FFT transformation of five-level diode-clamped inverter.

inverter. A systematic approach for designing a nonlinear internal controller for the converter has been developed. For the STATCOM with five-level inverter, the mitigation of the power quality problems is effective. The strategy has been validated with extensive MATLAB Simulation results. 


\section{Appendix}

The following test data is considered for MATLAB Simulation.

Three-phase source (utility):

$100 \mathrm{MVA}, 66 \mathrm{KV}, R_{s}=0.8029 \Omega, L_{s}=16.85 \mathrm{MH}$.

Transformer rating:

$100 \mathrm{MVA}, 66 / 11 \mathrm{kV}, R_{l}=0.087 \Omega$,

$X_{l}=0.3267 \Omega$, both $R_{l}, X_{l}$ referred to the primary.

Inverter rating:

+/- 10 MVAR, $11 \mathrm{kV}$ on secondary side of transformer.

$V_{\mathrm{dc}}=3400 \mathrm{~V}$ is the rated dc bus voltage for six-pulse inverter.

$V_{\mathrm{dc}}=4500 \mathrm{~V}$ is the each DC source in five level inverter without transformer.

$R_{\text {on }}=0.01 \mathrm{ohm}$.

$X_{l s}=0.1936 \Omega$ referred to $11 \mathrm{kv}$ side.

\section{References}

[1] C. Hochgraf and R. H. Lasseter, "A transformer-less static synchronous compensator employing a multi-level inverter," IEEE Transactions on Power Delivery, vol. 12, no. 2, pp. 881-887, 1997.

[2] G. Yalçinkaya, "Characterization of voltage sags in industrial distribution systems," IEEE Transactions on Industry Applications, vol. 34, no. 4, pp. 682-688, 1998.

[3] W. N. Chang, "A flexible voltage flicker teaching facility for electric power quality education," IEEE Transactions on Power Systems, vol. 13, no. 1, pp. 27-33, 1998.

[4] J. Rodríguez, J. S. Lai, and F. Z. Peng, "Multilevel inverters: a survey of topologies, controls, and applications," IEEE Transactions on Industrial Electronics, vol. 49, no. 4, pp. 724-738, 2002.

[5] Y. H. Liu, J. Arrillaga, and N. R. Watson, "A new STATCOM configuration using multi-level DC voltage reinjection for high power application," IEEE Transactions on Power Delivery, vol. 19, no. 4, pp. 1828-1834, 2004.

[6] A. K. Jain, K. Joshi, A. Behal, and N. Mohan, "Voltage regulation with STATCOMs: modeling, control and results," IEEE Transactions on Power Delivery, vol. 21, no. 2, pp. 726-735, 2006.

[7] D. Jovcic and R. Sternberger, "Frequency-domain analytical model for a cascaded multilevel STATCOM," IEEE Transactions on Power Delivery, vol. 23, no. 4, pp. 2139-2147, 2008.

[8] R. Sternberger and D. Jovcic, "Theoretical framework for minimizing converter losses and harmonics in a multilevel STATCOM," IEEE Transactions on Power Delivery, vol. 23, no. 4, pp. 2376-2384, 2008.

[9] C. D. Townsend, T. J. Summers, and R. E. Betz, "Multigoal heuristic model predictive control technique applied to a cascaded H-bridge statcom," IEEE Transactions on Power Electronics, vol. 27, no. 3, pp. 1191-1200, 2012.

[10] K. Sano and M. Takasaki, "A transformer less D-STATCOM based on a multi voltage cascade converter requiring no DC sources," IEEE Transactions on Power Electronics, vol. 27, no. 6, pp. 2783-2795, 2012. 

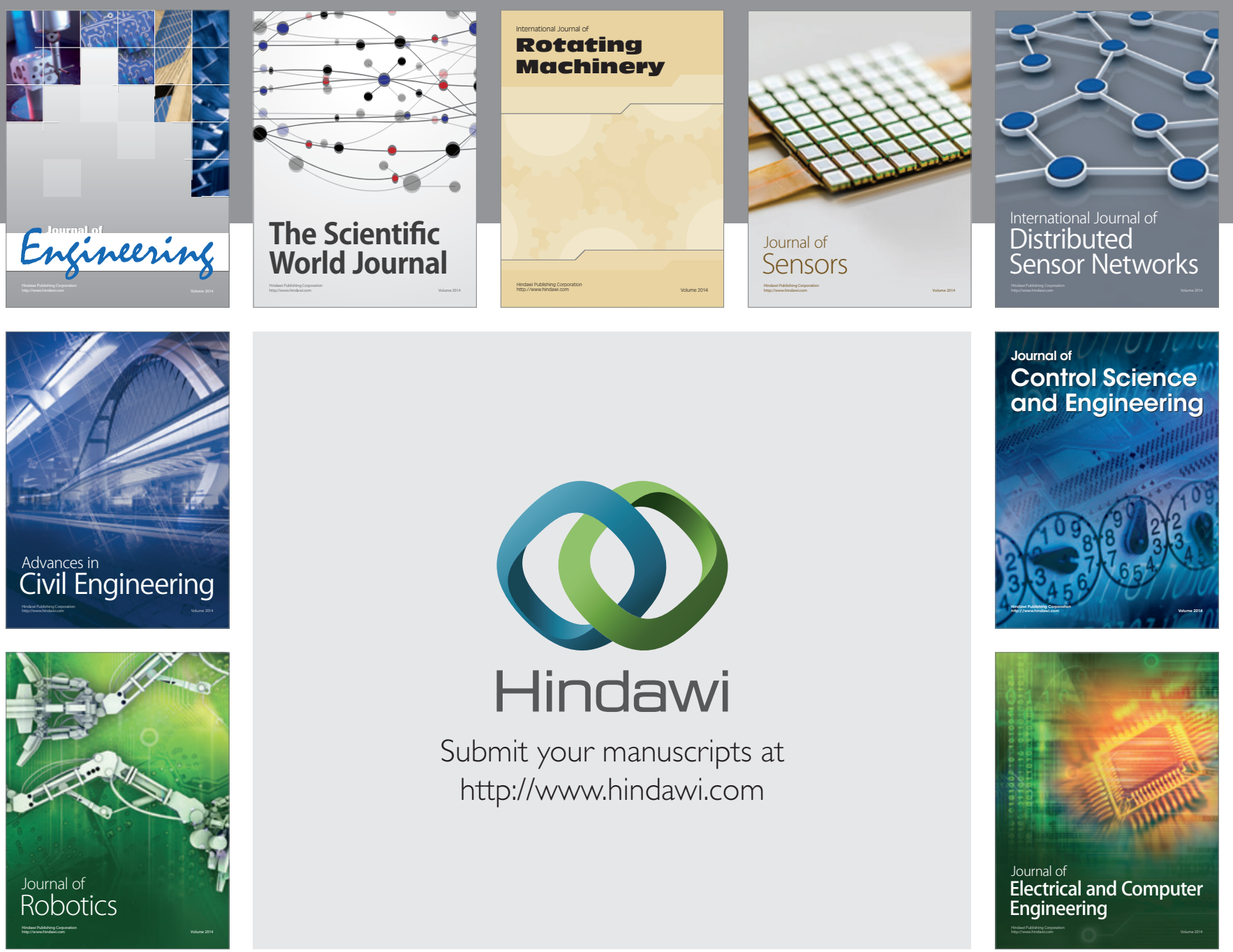

Submit your manuscripts at

http://www.hindawi.com
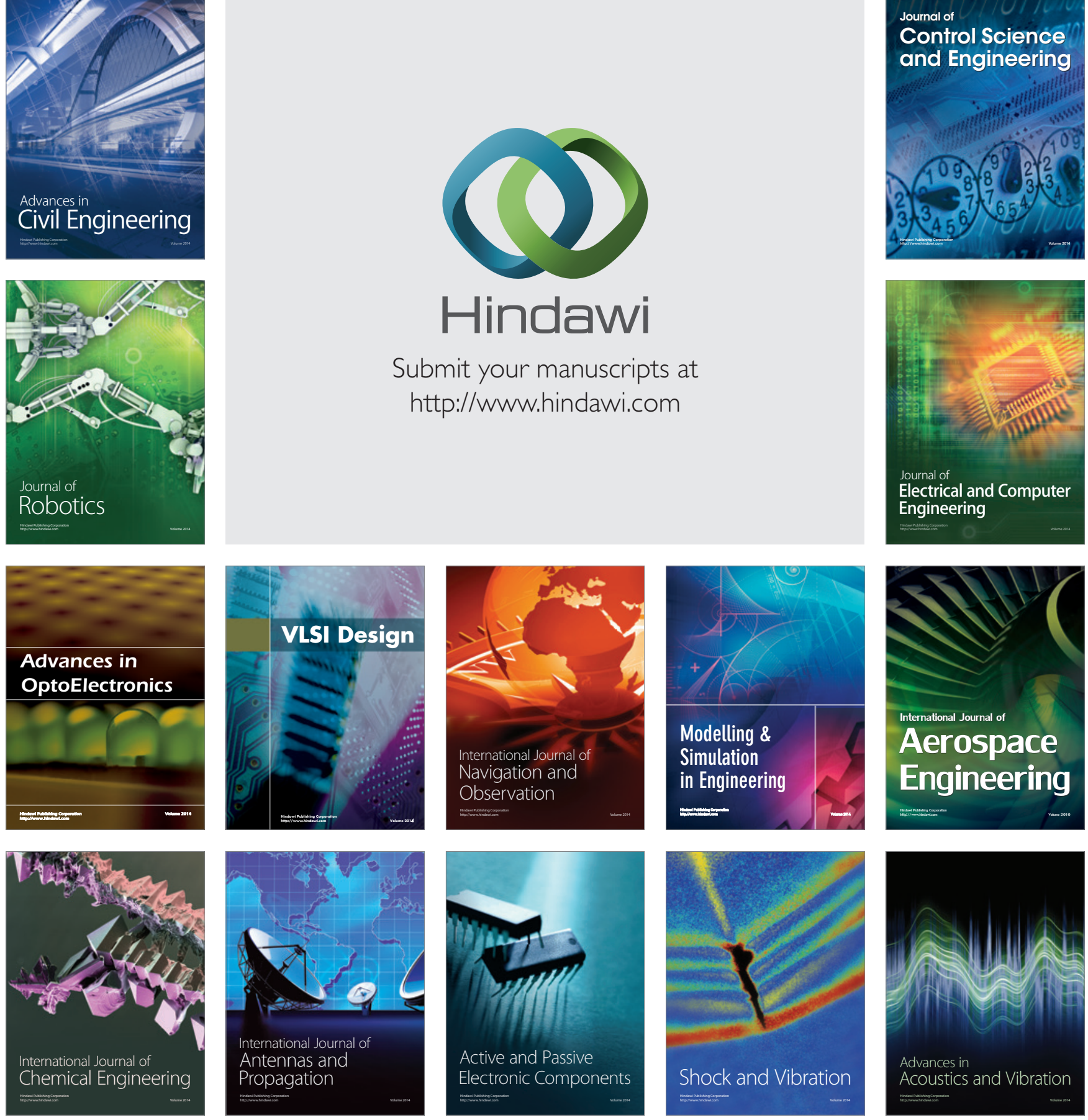